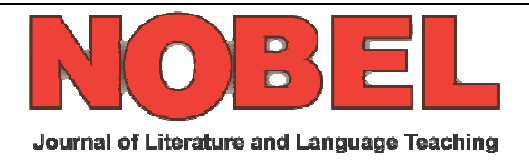

Volume 11, Number 2, September 2020, 217-233

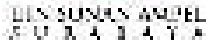
available at http://jurnalfahum.uinsby.ac.id/index.php/nobel/article/view/299

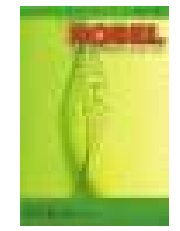

DOI: 10.15642/NOBEL.2020.11.2.217-233

\title{
POLITENESS MARKERS IN TEACHERS' REQUEST IN CLASSROOM INTERACTIONS
}

\author{
Hieronimus Canggung Darong ${ }^{\circledR 凶}$, A. Effendi Kadarisman ${ }^{2}$, Yazid Basthomi ${ }^{3}$ \\ ${ }^{1}$ Universitas Katolik Indonesia Santu Paulus Ruteng, Jl. Jend. A. Yani 10, Ruteng, Manggarai, Indonesia \\ ${ }^{2}$ Universitas Negeri Malang, Jl. Semarang 5 Malang, Indonesia \\ ${ }^{3}$ Universitas Negeri Malang, Jl. Semarang 5 Malang, Indonesia
}

\begin{tabular}{l}
\hline Article Info \\
\hline Article History: \\
Received June 2020 \\
Accepted July 2020 \\
Published September 2020 \\
\hline Keywords: politeness \\
speech act, pol \\
marker, and request \\
\hline
\end{tabular}

\begin{abstract}
This study is an attempt to examine politeness markers employed by Indonesian English teachers in classroom interactions. Purposefully chosen English teachers were observed, audio-recorded, and analyzed by using the politeness principle and Gricean cooperative principle. The conversation analysis revealed that to mitigate the illocutionary act of request, aside from using internal modifiers at most (consultative device, politeness markers, hesitators, hedges, playdowns, committers, down-toners, understaters), the teachers also used external devices as an adjunct to the head acts (grounder, sweetener, and disarmer). Besides, teachers intentionally violated the maxim for the sake of extending the talk. Further research needs to include more participants and instruments in a wider area of analysis.
\end{abstract}




\section{INTRODUCTION}

Politeness is a generic term in which linguistic rules are applied in real communication. In terms of its coverage, politeness is regarded as a linguistic expression of saving someone's face during communication. This expression, indeed, is very dependent in a way that demonstrates the reflection and awareness of people and or culture where it belongs to. In this regard, one might be considered being polite but not certainly for other people. Although this is varied among cultures, the basic function is still similar in terms of underlining the message being conveyed during communication. Thus, politeness is associated with the rules of language, which are differently contextualized in the mind of language users and in the culture.

Like other aspects of pragmatics, politeness serves as basic rules to carry the illocutionary force of a particular utterance. Pinpointing the conception of speech act as a basic rule to language expressions, politeness is an integral part of successful communicative competence which, in turn, entails pragmatic competence in such a way that the interlocutor's ability might help to verbalize and subsequently realize their proper linguistic actions which fit both speaker, their intentions, and context in use (House, 2003). In this respect, to verbalize and realize the actions, politeness covers the ideas of systematic rules of language or principles such as directness and indirectness, and cooperative principles, which all are functioned to enact the language as a means of sharing the speaker's interpersonal intentions through utterance and action done by interlocutors.

Politeness was first examined at the level of words and sentences. However, as the development of pragmatics and conversation analysis has unfolded, it has come to be investigated at the discourse level (Lakoff, 2005). Considering what words or sentences are used and who the speakers are is insufficient to convey the illocutionary acts without viewing the context where they occur. As such, the strategy is entailed in such a way that it might empower the force of the speaker's utterance, fits his or her intention to the interlocutors, and the context where they should belong to. This idea has attracted a deep passion for many researchers to reveal in their studies.

Studies have been done to reveal what and how politeness is employed at the level of words, sentences, and at the discourse level both in learners' spoken and written request (Eshghinejad \& Moini, 2016; Mohammadi, Nejadansari, \& Manijeh, 2015; Ren \& Gao, 2012; Li \& Taguchi, 2014; Wijayanto, Prasetyarini, \& Hikmat, 2017; Yazdanfar \& Bonyadi, 2016; Zhu, 2012). The studies have revealed that social distance, culture, rank, gender, and status routinely determine the politeness strategy employed in interaction. These four ways of assessing politeness (contexts) are proven as the frontline factors uttering learners' politeness 
expressions, whether they belong to the category of direct or indirect. Moreover, these strengthen politeness as a verbal or written expression, which is realized through various illocutionary forces to carry a particular illocutionary act.

Besides, different aspects of politeness in general and politeness markers, in particular, have also been investigated and mainly focused on learners' gender and culture. The research studies have revealed that those two variables strongly determine the perception of politeness (Ahmadian, 2010; Niroomand, 2012). While these two aspects are regarded as the key factors of politeness perception, the realization of politeness in different speech acts like an apology, refusal, and disagreement (Behnam \& Niroomand, 2011; Tamimi Sa'd \& Mohammadi, 2014) is delineated as something dreadful for it requires pertinent strategy in carrying its illocutionary force. As such, great attention to its illocutionary force is a crucial aspect of politeness. In terms of politeness markers, Tajeddin and Pezeshki (2014) have revealed that the use of tasks might be more beneficial in teaching politeness markers to the learners. Further, they argued that both input and output tasks contribute to the acquisition of politeness markers. As such, the finding proves that politeness is teachable in a classroom context through intervention during teaching-learning processes.

A considerable amount of research has been conducted concerning learners' speech acts of politeness to the exclusion of a specific focus on teachers' politeness markers used particularly in a request. The small number of studies conducted on teachers' politeness markers may be due to the presupposition that the class is not outlined and tightly structured. The class is no more drawn on power relations and emphasizes more on equality and partnership. However, this presupposition might only be seen as the context of interaction model (IRF/initiation, Response, and Feedback), which is not feasible and still, anyhow, debatable to a certain setting. Moreover, the power does not solely rely on authority but also the illocutionary force of the utterances carrying certain intentions of the speakers (Carassa \& Colombetti, 2015). To contribute to the gap and the existing insights into the politeness in EFL contexts, this study focused on the politeness markers/structures of request employed by teachers in classroom settings. This is a prickly issue as it generally contributes toward the creation of interactive communication and specific benefits for sharing interpersonal responsibility classroom talks. Succinctly, the investigation of teachers' politeness markers needs conducting in such a way that they might function well as a discourse management tool of classroom interactions. 


\section{LITERATURE REVIEW}

\section{Politeness theory}

As we communicate with others, a form of social action must be there. However, a prerequisite to justify the statement in question should be clear. Communication is not only a form of uttering words and sentences but also a form of activity that can be analyzed in terms of a sequence of communicative acts (discourse level) performed by the interlocutors. This is, actually, concerned with the intention and cooperation between the speaker and hearer regarding the message being carried in certain utterances. As such, different theoretical approaches have been proposed by Austin (1962) with the inclusion of the study of communicative acts (speech act theory and communication principles). These two views stress sharing interpersonal responsibility between the speaker and interlocutor and sharply stifle that their communication is a form of social action.

Pinpointing Austin's (1962) theory of speech acts, politeness is an utterance containing three facets, namely a locutionary act, an illocutionary act, and a perlocutionary act. The former is concerned with the description of what the speaker says, weaving the speaker's experience at the moment of speaking - the later deals with the speaker's intention behind the utterance to be carried to the interlocutors. While the previous facets are concerned with the surface and perception of politeness, the last is more on action resulting from the politeness illocutionary force (the illocutionary force in action).

Along the line of this argument, the basic principle of politeness is to take the feelings of others into account and makes others feel comfortable. As such, they are comfortable deals with the hearer's perception toward the illocutionary force of a particular utterance. As delineated by Goffman (1967), politeness is the perception of an individual shown to another through avoidance or presentation of rituals. Politeness serves as a function to avoid conflicts, which might occur in speech events among the participants involved. Subsequently, to do this, keeping someone's face is required. Although the idea of the face is different in terms of cultural background, the basic principle is still similar in a way that communication should be maintained.

Concerning the face, Brown and Levinson (1978) have classified face into two, namely negative and positive. Negative face is our need to act without imposition and positive face as our desire to be liked and admired by others. Furthermore, another term is also coined which is so-called face-threatening acts (FTAs) to deal with acts such as disapproval or contempt which might challenge someone's positive face and acts, for example, requests for action, that limits someone's freedom and challenge his or her negative face. Misunderstandings and breakdowns might happen from FTAs (Yazdanfar \& Bonyadi, 2016). 
Regardless of its weakness in terms of the exclusion of the community's sense of social rights and or particular linguistic community's face claims and face sensitivities, the concepts still underline the principle of strategy in the illocutionary force of the utterance. Brown and Levinson (1978) and Leech (1983) have mentioned that for the sake of politeness, people might use more indirect forms than the direct ones, which might be as face-threatening. This is due to the optionality and the tentativeness of its force. In requests, a direct speech act is regarded as being impolite or rude. So, to mitigate or soften the effect of speech acts, and to increase the face of the message communicated, speakers may optionally state their utterances indirectly, which does not meet the illocutionary force of the utterance (Parker \& Riley, 1994).

\section{Politeness markers}

In expressing politeness, context and linguistic expressions are very important to consider. Regardless of non-linguistics expressions, the two aspects play a vital role in carrying the message. Social status, rank, gender, intimacy, or social distance are some contexts to include in politeness expressions. Aside from them, linguistic expressions are useful in such a way that they might enact the politeness. One of the linguistic expressions that can be used is politeness markers. It has plenty of ways in carrying out the effects of politeness on interlocutors, all of which are used to lower the degree of imposition on the addressee (Watts, 2003)

In many cases of politeness in a request, the use of direct speech acts is considered as being impolite or rude. For the sake of softness or mitigation of the effect of speech acts, speakers may use an indirect level by using a syntactic form, which can be done through some politeness markers. The indirect way of expressing politeness does not match with its illocutionary force of the speaker's utterances (Parker, 1994). This is corroborated by Yule (1996) and Thomas (1983), saying that since the speech act of request is a kind of imposition on the hearer, the speaker had better avoid a direct request in most circumstances. Besides making the speech more interesting, the use of such form aims at increasing the face of the message communicated. Thus, the direct request is impolite because it limits the hearer's freedom, and indirectness is a way in which speakers prefer to increase the degree of politeness.

Politeness in request strategies is classified into three levels of directness and nine strategy types (Yazdanfar \& Bonyadi, 2016). They are, first, the most direct explicit level, which includes mood derivable, explicit performatives, hedged performatives, locution derivable, and scope stating. Second, the conventionally indirect level involving language- 
specific suggestion formulas and reference to preparatory conditions. Third, the nonconventionally indirect level, which includes strong hints and mild hints. Further, speakers may also use some external (getting a pre-commitment, grounder, sweetener, disarmer, cost minimizer) and internal modifications (downgraders both syntactically and lexically and upgraders by using intensifiers and expletives) to soften the impact of requests as FTAs. Such modification devices should be used in such a way that they might function to either mitigate or aggravate the request.

Politeness markers are used in terms of their functions to level and the degree of the imposition and the force of an utterance. As such, some scholars have coined distinctive taxonomies of politeness markers such as Brown and Levinson (1987), Crystal (1975), and Edmonson and House (1981) who categorized all the markers into two groups: 'hedges' to lower the imposition of an utterance, and 'boosters' to strengthen the force of the utterance. However, as cited in Tajeddin and Pezeshki (2014), the taxonomy proposed by House and Kasper (1981) is the most common taxonomy used. The taxonomy includes many markers that could be used to pinpoint politeness. They are delineated as politeness markers such as "please and if you wouldn't mind" expressions put in an utterance and functioned to ask for interlocutor's cooperation, and play-downs devices uttered to decrease the perlocutionary effect of an utterance. The use of past tense, consultative devices dealing with the way how speaker asks for cooperative action by the addressee, hedges such as 'kind of,' 'sort of,' anyhow, 'downtoners such as only, just, simply, possibly, and probably which are concerned with the way how to set off the effect of the speaker's utterance, and committers dealing with devices used to lower the extent to which the speaker commits her/himself to the proposition of her/his utterance.

Few research studies have been carried out in the use of linguistic markers. Taking a corpus-based approach (Barbieri, 2015) investigated the use of involvement markers across class sessions representing three situational factors that define the university setting: academic discipline, level of instruction, and class size. It was found that these factors have relatively little influence on involvement in language, suggesting that involvement is pervasive in American classroom talk. Further, the involvement tends to be more common in small courses as the instructors have many chances to express their linguistic expressions. Interestingly, the study was concerned with the instructors' linguistic features employed during the classroom talk, which was scarcely investigated. However, specific categorization on such linguistic expressions was not done.

In a more specific way, Tajeddin and Pezeshki (2014) investigated the politeness markers of EFL students using film-driven input-enhancement tasks and output tasks. 
Pinpointing the framework proposed by (House \& Kasper, 1981), the study revealed the beneficial effect of teaching politeness markers through the two tasks. Both groups improved significantly in their comprehension production of politeness markers. Drawing on the Speech Act Theory, the study conducted by Yazdanfar and Bonyadi (2016) compared request speech acts in the daily interaction between Persian and English speakers based on directness level and supportive moves. The study revealed that the English speakers employed more politeness markers in conventionally indirect ways as their strategies in interaction than the Persian speakers did, and the Persian speakers used more non-conventionally indirect strategies than the English speakers did.

All the studies enact the students as an interesting learning target to reveal. However, the teacher's position is something beyond in terms of his or her way of using linguistic expressions, which is an interesting aspect to see in his or her teaching role in the classroom talk. As such, the gap inspires the present study to investigate more specific features of politeness markers employed by the instructors in the classroom setting.

\section{METHOD}

The present study is part of a larger corpus project of UMSpEAKs (Universitas Negeri Malang Spoken English in Academic Kontexts). The participants of this study were four English teachers at Universitas Negeri Malang Indonesia. Classes and teachers were selected voluntarily and subsequently were observed and recorded once during their interactions with the students in the academic year of 2019. While being direct non-participant observers, we noted any single utterances containing politeness markers on request to support the data recording. Adapting from Gardner (Marie and Rohan, 2011), the observed classroom interactions of the four English teachers were fully transcribed. Then, they were analyzed in terms of politeness markers using the taxonomy proposed by House and Kasper (1981). In addition to this taxonomy, the use of Blum-Kulka and Olshtain's Cross-Cultural Study of Speech Act Realization Pattern (CCSARP) (1984) and Gricean cooperative principle (Leech, 1983) were robust and beneficial to reveal the teachers' politeness markers. The result of the analysis, then, was cross-checked respectively to the next four teachers for the sake of possible prejudices. Subsequently, the result of this verification strategy was finally crosschecked with the field notes to stifle the final analysis. 


\section{RESULTS AND DISCUSSIONS}

The following table is the distribution of politeness markers used as internal modifiers by instructors or teachers (House and Kasper 1981; Blum-Kulka and Olshtain's, 1984).

Table 1. Politeness markers

\begin{tabular}{lllll}
\hline Markers & T 1 & T 2 & T 3 & T 4 \\
\hline Politeness markers & 8 & 7 & 11 & 9 \\
Play-downs & 7 & 5 & 10 & 6 \\
Consultative Devices & 35 & 54 & 35 & 27 \\
Hedges & 3 & 7 & 4 & 5 \\
Understaters & 2 & 3 & 4 & 2 \\
Downtoners & 4 & 3 & 4 & 2 \\
Commiters & 5 & 4 & 3 & 3 \\
Hesitators & 7 & 5 & 10 & 7 \\
\hline
\end{tabular}

Note: T: Teacher

Looking at the data in Table 1, all teachers employed different kinds of markers resulting from the classroom discourse moves during the interactions. Out of 8 markers, consultative devices were the most marker used by the teachers. It indicated cooperation between teachers' and students' commodity exchanges.

Table 2. Distribution of Politeness Markers as external modifiers

\begin{tabular}{lllll}
\hline External Devices & T1 & T2 & T3 & T4 \\
\hline Grounder & 4 & 3 & 3 & 2 \\
Sweetener & 3 & 4 & - & 2 \\
Disarmer & 2 & 2 & 3 & 3 \\
\hline
\end{tabular}

Although external devices were rarely used and only as an optional clause, they were very influential in managing classroom talk. Out of 3, grounder was the most external device used by the teachers. As such, the teachers invited student responses by convincing them with information preceding the request proposition. The information was given in such a way that it could indirectly modify the illocutionary force of request.

Table 3. Distribution of Maxim

\begin{tabular}{|c|c|c|c|c|c|c|c|c|c|}
\hline Maxim & T1 & T2 & T 3 & T4 & \multirow{5}{*}{$\begin{array}{c}\text { Maxim } \\
\text { violation }\end{array}$} & T1 & T2 & T3 & T4 \\
\hline Relation & 198 & 242 & 212 & 192 & & 4 & 3 & 6 & 5 \\
\hline Quality & 204 & 245 & 218 & 195 & & - & - & - & - \\
\hline Quantity & 202 & 239 & 213 & 191 & & 2 & 3 & 5 & 4 \\
\hline Manner & 204 & 245 & 218 & 195 & & - & - & - & - \\
\hline
\end{tabular}

The overall data suggests a range of teachers' politeness strategies in the request. As previously noted in previous studies (Tajeddin \& Pezeshki, 2014; Yazdanfar \& Bonyadi, 2016), politeness markers were predominantly utilized as a strategy to request. Similarly, in 
this study, the teachers used internal devices, which are mostly in the form of syntactical downgraders. In addition to the internal devices, the teachers employed some external devices appearing in the immediate context of speech acts as optional clauses. At this point, politeness markers were used as linguistic expressions to signal the politeness, which is in line with some previous research studies (Behnam \& Nirromand, 2011; Chang, 2008; Niroomand, 2012; Zhu, 2012).

As such, the consultation devices might be functioned to ask cooperation and totally from the I (speakers)-perspective. This is acceptable as the one who initiates and controls the talk was the teacher whose authority and rank are higher than the students. Subsequently, politeness markers such as "please and if you don't mind" were used similarly in request cooperation, all of which were used to lower the degree of imposition on the addressee. Meanwhile, hesitators appeared where pauses are necessarily done to confirm the student's response. The use of such pauses was beneficial to negotiate meaning. At this point, the teachers cared about interpersonal responsibility in such a way that they shared their intentions with the students. The aims were to respect student's responses regardless of being the wrong response they received. In addition, pauses were pertinent to soften the impact of direct request. Other markers were also found, such as play-downs, committers, understaters, hedges, and downtoners. The following extracts illustrate the use of those devices.

\section{Extract 1}

T: Do you think I could delete all?

S: No.... only D?

$\mathrm{T}: \mathrm{D}$ or $\mathrm{E}$ ?

S: D

T: What about the other?

R: How many paragraphs do you have to have?

S: Three

$\mathrm{T}$ : What about the topic sentence? Would you mind opening your book?

This extract shows how the teacher asked for the cooperation to delete the wrong answer. In this regard, the cooperation was made in the I (speaker)-perspective as the agent of action and categorized as a strong hint of non-conventionally indirect. Unlikely, "what you mind opening your book" was in the hearer (students)-perspective and was regarded as query preparatory of conventionally indirect. Both were categorized as lexical (phrasal) downgraders internal modifiers, which mitigate the force of the question as a request. The use of consultation devices might be helpful in a way that they keep the actual social interactions that speakers try to achieve in their communicative acts (getting help and sharing feelings or attitudes). Relying on the mutual assumptions of cooperativeness and the nature of context, the speaker (teacher) tried to achieve the intended effects of sharing their social intention with 
their interlocutors and creating expectations of cooperation intentionally (Carassa \& Colombetti, 2015).

\section{Extract 2}

T: OK. Thank you. Have you all got the turn to share the story?

Did you find something interesting about your friend's story?

S: Yes. We have got many.

T: Good. Share with us, please? Ok, Nia. Could you please stand up? So everyone can see your face $\downarrow$ Hello $\uparrow$ listen, please $\downarrow$

The extract shows that the word "please" was used in the context of asking students to share the story and uttering a little bit louder voice. To soften the request, the teacher used it as a modifier occurring within the speech act as a supportive move, which can be either downgrader or upgrader. Subsequently, they both functioned to mitigate and enhance the illocutionary force of the request. The former and the last "please" belonged to the intensifier that is preceded by phrasal upgraders. Referring to directness level, the first and the last belonged to mood derivable and the second is categorized as query preparatory of conventionally indirect. At this point, the appearance of the marker "please" was a strategy to soften the impact of direct request, which is rude and impolite. It is in line with the argument that a request is a kind of imposition on the hearer, and; the speaker had better avoid a direct request as it is rude and impolite (Brown \& Levinson, 1987; Leech, 1983; Yule, 1996).

\section{Extract 3}

T: Right. This is also a modification because it is a phrase. What phrase?

S: Noun Phrase.

T: Ahh.. common $\uparrow$ Are you sure? What is the head?

S: exhausted.

$\mathrm{T}$ : the head is exhausted. So this is a noun phrase.

The linguistic expression "ahh" was a non-lexical phonetic material and functioned to soften the directive speech act. Instead of saying disagreement expression, the speaker (teacher) rather used this expression. In addition, this marker was used in the context of warning the hearer (students) of giving a wrong response and requesting them to reconsider and provide a new response (extending the talk). This was another strategy to soften the illocutionary force of the directive speech act.

Aside from the three mentioned, the teachers used some play-downs, downtoners, hedges, understaters, and commiters as politeness markers. These structures were used to get the hearer (students) to perform some kind of action. The following extracts provide examples of how teachers used them in their interaction (extract 4 and 5). Besides, in Extract 5 , there is an example of maxim violation as another pragmatic strategy used by teachers in their request. 


\section{Extract 4}

T: Why do you come here?

S: For studying.

T: OK. Do you think she understands my question?

S: Yes, she does.

T: I don't know why she understands my question $\downarrow$ Could you tell me?

S: She knows the context.

T: Right. I was thinking you might add context there. $\downarrow$ It is also one aspect of being communicative. I was wondering if you have that one.

The extract shows how the teacher reduced the perlocutionary effect of directive speech act on the students. The teacher requested them to put context as one of the requirements in authentic assessment. Instead of asking direct requests, the teacher used play-down as an internal modifier to soften the impact of the request as an FTAs. This appeared within the speech act and functioned to mitigate its force (downgrader). Another interesting part of this extract was the use of grounder (I don't know why she understands my question. Can you tell me?). This external modifier was preceded by a reason (an adjunct to the head) before coming to the utterance as a request. Likely, the function indirectly modified the illocutionary force of request. However, this appeared in the immediate context of the speech act and is an optional clause.

\section{Extract 5}

T: All right. Now. Who is next? John, please!

S: ((The flood was caused by the storm)) (The student mispronounced the word flood)

T: What did you say? I don't think everyone here can hear your voice. You have a beautiful voice. Could you speak louder, please?

$\mathrm{S}$ : The flood was caused by the storm!

T: OK. Good... I think you can also find two other causes in the text.

T: OK. What about the greenhouse?

S: Yes. That is one of the causes.

T: Well, could you explain why?

The extract enacts the speaker (teacher) to commit himself to the propositional content of the utterance. These devices, the so-called committers, were employed as an internal modifier to lower the extent of directive speech act. In this respect, the teacher made sure the propositional content of his utterance and yet still as a request for the student to perform an action. In other words, the locutionary force was employed from the I (teacher)-perspective, but the illocutionary force was from the hearer (student)-perspective. As such, form and function can be separated. When the form and function of the utterances were examined together, it became evident that a relationship existed between the two (Carr, Schrock, \& Dauterman, 2012; Frazier, Dillon, \& Clifton, 2017; Freed, 1994). In addition to the internal modifier, the politeness marker was used in the form of an external modifier, that is, sweetener (You have a beautiful voice. Could you speak louder, please?). This device, similar 
to the internal modifier, functioned as an illocutionary modification. The way to modify was by putting it as an adjunct to the head in the immediate context of the utterance.

Another pragmatic aspect of the politeness principle shown in Extract 8 was Grice's concept of maxim violation. The teacher violated the maxim of relevance (relation) and quantity. (T: What about green house?). In this respect, the teacher gives unnecessary information, which is not relevant as he required them to see the other two causes in the text. However, the teacher made it purposefully to let the student explore their idea (T: Well, could you explain why?). At this point, the teachers tried to extend the talk by violating the maxim of relevance.

The overall data of the present study shows the use of politeness markers and maxim principles in producing speech acts of request. In this context, a speech act is a linguistic expression that has a performative function, mostly as a request for students to do an action. Each type is associated with a particular illocutionary act. This act can be stated both in direct and indirect ways. Illocutionary acts are expressed directly when the syntactic form of utterances matches its illocutionary force. However, in many cases, as in request, it is regarded as being impolite. Subsequently, to mitigate or to soften the impact of the request, the speaker may use indirect utterance, that is, utilizing a syntactic form, which does not match the illocutionary force of the utterance as found by Yazdanfar and Bonyadi (2016). Referring to this, the present study corroborates previous findings in a way that politeness is a matter of choice of being direct or indirect (Manik \& Hutagaol, 2015; Mohammadi, Nejadansari, \& Manijeh, 2015). In this regard, the use of politeness markers found in this study was employed in the form of indirect utterances employing both internal modifiers (syntactic interrogative downgraders and lexical consultative downgraders). They were used as linguistic expressions (except hesitators) by teachers to show politeness, which does not match the illocutionary force of request. Saying it differently, the modification devices, as shown in the findings, might mitigate the illocutionary force of the request by using indirect utterances.

In addition to the internal modifiers, the use of grounder, sweetener, and disarmer as external devices was also found. Following Blum-Kulka and Olshtain's (1984) and House and Kasper's (1981) framework of the level of directness to signal the politeness, the utterances illustrated in the extracts are regarded as teacher's strategies to modify the illocutionary speech acts of request. As such, the external modifications, as adjuncts to the head, are functioned to modify (mitigate) the illocutionary force of request or to decrease the degree of directness. In other words, this study mirrors the previous studies that, aside from internal modifiers, the directness can be mitigated (face-threat mitigators) by using some modification 
devices, both external and internal devices (Tajeddin \& Pezeshki, 2014; Yazdanfar \& Bonyadi, 2016).

Interestingly, while very useful in categorizing and understanding illocutionary speech acts in isolation, the data do not show how the students understand them. In other words, the tools that students have to understand the illocutionary value to a speech act are somewhat unclear. Luckily, as cited in Christison (2018), Grice says that when we perform illocutionary acts, we engage in rule-governed behavior. Furthermore, four general principles or maxims (cooperative principles) were offered to lead interlocutors in identifying presuppositions, thereby enabling students to assign illocutionary value. It should be kept in mind; however, when the principles were violated in purposeful ways, there is an obvious reason for the violation. By offering irrelevant information, the speaker is either communicating or trying to have something (Christison, 2018). In this context, teachers intentionally violated the maxim for the sake of managing conservation and let the topic open. As such, the violation (maxim of quantity, relation) is beneficial to get the response and provoke students thinking.

The relevant question is, "Should the teachers be polite to their students?" The social status of the speaker (teacher) or the authority is higher than the students?" As such, the assessment of the request strategy relies on the social distance and power of the participants. Since the teacher's status is higher than the student's, the assessment of directive request still goes on interpersonal responsibility in terms of sharing a good proportional intention to the students. This is corroborated by Zhu (2012), noting that request strategies assessment must be assessed in situational factors of social power, rank, and social status of imposition. Asymmetric power relations and social distance affect the use of politeness (Eshghinejad \& Moini, 2016).

Moreover, previous findings suggest that politeness might be reached when one or more maxims are fulfilled (Manik \& Hutagaol, 2015). However, as it is previously mentioned in the introduction part, this presupposition might only be seen as the context of interaction model (IRF), which is not feasible and still, anyhow, debatable to a certain setting. The class is no more drawn on power relationship and emphasize more on equality and partnership. Moreover, the power does not solely rely on authority but also the illocutionary force of the utterances carrying the certain intention of the speakers (Carassa \& Colombetti, 2015; Darong et al., 2020). The violation is intentionally done for the sake of the value of interpersonal relationships. As noted by Yule (1996), politeness strategies are very crucial to examine as people employ them in their social interaction and specific contexts, knowing what to say, how to say, and to whom be said. The term context here is not only concerned 
with physical context but also refers to the proper usage and function of utterance with a particular goal, such as to extend the talk or response as found in this study.

\section{CONCLUSION}

This study deals with politeness markers that were employed by teachers in an Indonesian EFL classroom. Concerning the findings, some conclusions can be drawn. First, the use of external devices, which are also called adjunct to the head acts or enquirers (grounder, sweetener, and disarmer) and internal modifiers, were used by the teacher to soften the impact of requests as FTAs. Second, in the meantime, in producing the speech act of request, teachers intentionally violated the maxim for the sake of a particular goal that is to share the interpersonal responsibility of extending the talk.

This present study suffered from some limitations that should be taken into account for further studies. First, as this study only investigated teachers' politeness markers involving maxim analysis at the university level, there is no guarantee that what has been found is similar to other teachers at other school levels. As such, the aspects to analyze might be possibly seen in a large number of participants and necessarily investigated from different angels involving other variables and more instruments of data collection. Furthermore, the present study was conducted in an observational way of dealing with an authentic classroom language. Further studies might be carried out by giving more concerns on intentional interventions to investigate whether a certain pragmatic aspect is teachable or not. As such, the classroom is consequently viewed as a setting in which learners may learn something as a result of well-planned pedagogical actions governed by pragmatic acquisition through some behavior and languages. Second, since this present study only analyzed teachers' politeness markers in classroom interaction, other pragmatic aspects (questioning function and questioning strategy and other speech acts) and other aspects of classroom interaction (interactional features, the pattern of interaction) can be further investigated.

\section{REFERENCES}

Ahmadian, M.J., \& Dastjerdi, H.V. (2010). A comparative study of the perception of politeness of American reprimands by Iranian EFL learners and Americans. The Social Sciences, 5(4), 359-363. DOI: 10.3923/sscience.2010.359.363

Austin, J. L. (1962). How to do things with words. Oxford, UK: Oxford University Press.

Barbieri, F. (2015). Involvement in University Classroom Discourse : Register Variation and Interactivity. Applied Linguistics, 36(2), 151-173. DOI: 10.1093/applin/amt030

Behnam, B., \& Niroomand, M. (2011). An investigation of Iranian EFL learners' use of 
politeness strategies and power relations in disagreement across different proficiency levels. English Language Teaching, 4(4), 204-220. DOI: 10.5539/elt.v4n4p204

Blum-Kulka, S., \& Olshtain, E. (1984). Requests and apologies: A cross-cultural study of speech act realization patterns (CCSARP). Applied Linguistics, 5(3), 196-214. DOI: 10.12691/education-4-4-9

Brown, P., \& Levinson, S. C. (1978). Universals in language usage: Politeness phenomena. In E. N. Goody (Ed.). Questions and politeness: Strategies in social interaction, (pp. 256-289). Cambridge, UK: Cambridge University Press.

Brown, P., \& Levinson, S. C. (1987). Politeness: Some universals in language usage. Cambridge, UK: University Press.

Carassa, A., \& Colombetti, M. (2015). Interpersonal Communication as Social Action. Philosophy of the Social Sciences, 45(4-5), 407-423. DOI: 10.1177/0048393115580265

Carr, C. T., Schrock, D. B., \& Dauterman, P. (2012). Speech Acts within Facebook Status Messages. Journal of Language and Social Psychology, 31(2), 176-196. DOI: $10.1177 / 0261927 X 12438535$

Chang, W. (2008). Australian and Chinese perceptions of (im)politeness in an intercultural apology. Working. Pragmatics and Intercultural Communication, 1(2), 59-74.

Christison, M. (2018). Speech Act Theory and Teaching Speaking. The TESOL Encyclopedia of English Language Teaching, 1-6. DOI: 10.1002/9781118784235.eelt0712

Crystal D, D. D. (1975). Advanced Conversational English. London: Longman.

Darong, H.C, Kadarismann A.F., Basthomi, Y., Suryati, N., Hidayati, M. \& Niman, E.M. (2020). What Aspects of Questions Do Teachers Give Attention To? International Journal of Innovation, Creativity, and Change, 10(11), 191-208. Retrieved from: https://www.ijicc.net/index.php/volume-10-2019/149-vol-10-iss-11

Edmonson, W., \& House, G. (1981). Politeness markers. In English and German. In F. Coulmas (Ed.). Conversational routine: Explorations in standardized communication situations and prepatterned speech (pp.157-185). The Hague, The Netherlands: Mouton Publishers.

Eshghinejad, S., \& Moini, M. R. (2016). Politeness Strategies Used in Text Messaging: Pragmatic Competence in an Asymmetrical Power Relation of Teacher-Student. SAGE Open, 6(1),. DOI: 10.1177/2158244016632288

Frazier, L., Dillon, B., \& Clifton, C. (2017). Together They Stand : Interpreting Not-At-Issue Content. Language and Speech, 61(2), 1-28. DOI: 10.1177/0023830917714608

Freed, A. F. (1994). The form and function of questions in informal dyadic conversation. Journal of Pragmatics, 21(6), 621-644. DOI: 10.1016/0378-2166(94)90101-5

Goffman, E. (1967). Interaction ritual: Essays on face to face behavior. New York, NY: Anchor Books.

Hosoda, Y. (2015). Teacher Deployment of ' oh' in Known-answer Question Sequences. Classroom Discourse, 7(1), 58-84. DOI: 10.1080/19463014.2015.1099111

House, J. (2003). Teaching and learning pragmatic fluency in a foreign language: the case of English as a lingua franca'. In A. Martínez -Flor, E. Usó Juan, \& A. Fernández Guerra (Eds.). Pragmatic Competence and Foreign Language Teaching, (pp. 133-160). Castelló de la Plana: Publicacions de la Universitat Jaume I.

House, J., \& Kasper, G. (1981). Politeness markers in English and German. In: Coulmas F 
(Ed). Conversational Routine. Berlin: De Gruyter Mouton, (pp. 157 - 86., 157-186).

Lakoff, R.T., \& Ide, S. (2005). Introduction: Broadening the horizon of linguistic politeness. In R.T. Lakoff \& S. Ide (Eds.). Broadening the Horizon of Linguistic Politeness, (pp. 120). Amsterdam: John Benjamins.

Leech, G. (1983). Principle of Politeness. London, England: Longman.

Li, S., \& Taguchi, N. (2014). The effects of practice modality on the development of pragmatic performance in L2 Chinese. The Modern Language Journal, 98(3), 794-812. DOI: $10.1111 / \operatorname{modl} .12123$

Manik, S., \& Hutagaol, J. (2015). An Analysis of Teachers ' Politeness Strategy and Student's Compliance in Teaching-Learning Process at SD Negeri 024184 Binjai Timur Binjai North Sumatra-Indonesia. English Language Teaching, 8(8), 152-170. DOI: 10.5539/elt.v8n8p152

Marie, A. \& Rohan, B. (2011). Using Conversation Analysis in the Second Language Classroom to Teach Interactional Competence. Language Teaching Research, 15(4), 479-507. DOI: 10.1177/1362168811412878

Mohammadi, A.M., Nejadansari, D. \& Manijeh, Y. (2015). The Index of Pragmatic Uses and Functions of Well in University EFL Classroom Discourse: A Case Study in Iran. Taiwan Journal of TESOL, 12(2), 86-116.

Niroomand, M. (2012). An exploration of upper-intermediate Iranian EFL learners' perception of politeness strategies and power relation in disagreement. English Language Teaching, 5(10), 2012.

Parker, F., \& Riley, K. (1994). Linguistics for non-linguistics. Boston, MA: Pearson Education.

Ren, J., \& Gao, X. (2012). Negative Pragmatic Transfer in Chinese Students' Complimentary Speech Acts. Psychological Reports, 110(1), 149-165. DOI: 10.2466/07.17.21.28.PR0.110.1.149-165

Tajeddin, Z., \& Pezeshki, M. (2014). Acquisition of Politeness Markers in an EFL Context: Impact of Input Enhancement and Output Tasks. RELC Journal, 45(3), 269-286. DOI: $10.1177 / 0033688214555357$

Tamimi Sa'd, S., \& Mohammadi, M. (2014). A cross-sectional study of Iranian EFL learners' polite and impolite apologies Seyyed. Journal of Language and Linguistic Studies, 10(1), 119-136.

Thomas, D. (1983). An Invitation to Grammar. Bangkok: Thailand Summer Institute of Linguistics, Mahidol University.

Watts R.J. (2003). Key Topics in Sociolinguistics: Politeness. New York, USA: Cambridge University Press.

Wijayanto, A., Prasetyarini, A., \& Hikmat, M. H. (2017). Impoliteness in EFL : Foreign Language Learners ' Complaining Behaviors Across Social Distance and Status Levels. SAGE Open, (July-September), 1-15. DOI: 10.1177/2158244017732816

Yazdanfar, S., \& Bonyadi, A. (2016). Request Strategies in Everyday Interactions of Persian and English Speakers. SAGE Open, (October-December), 1-11. DOI: $10.1177 / 2158244016679473$

Yule, G. (1996). Pragmatics. Oxford, UK: Oxford University Press.

Zhu, W. (2012). Polite Requestive Strategies in Emails: An Investigation of Pragmatic 
Competence of Chinese EFL Learners. RELC Journal, 43(2), 217-238. DOI: $10.1177 / 0033688212449936$

\section{APPENDIX}

\section{Transcription Convention}

\section{Code}

$\mathrm{T}$

$\mathrm{S}$

$\dot{9}$

?

.

$\underline{\text { Line }}$

$=$

()

$\uparrow$

$\downarrow$

()

$(())$
Meaning

Teacher

student (response)

Period, end of a sentence

Question

Short time pause

An emphasis when speaking above the normal speech level Speaker's talk continues or the second speaker's talk is latched onto the first speaker without noticeable pause

Non-linguistic sounds, e.g. laughing

Rising intonation

Falling intonation

Comments by transcriber

Problematic hearing that transcriber is not certain

Adapted from Gardner (Marie and Rohan, 2011) 